\title{
UMA PROPOSTA DE FORMAÇÃO CONTINUADA DE PROFESSORES DE CIÊNCIAS E MATEMÁTICA NA INTERFACE DO AGIR COMUNICATIVO E DAS QUESTÕES SOCIOCIENTÍFICAS
}

\author{
A Proposal for the Continuing Education of Science and Mathematics \\ Teachers at the Interface of the Communicative Action and the socio- \\ scientific issues
}

Adriana Bortoletto ${ }^{1}$
Washington Luiz Pacheco de Carvalho

\begin{abstract}
RESUMO
O objetivo deste artigo é apresentar uma proposta teórica para a formação de professores de ciências e matemática na interface do agir comunicativo e as questões sociocientíficas. Defendemos neste trabalho, a necessidade da formação continuada de professores caso tenhamos o interesse de desenvolver a formação científica escolar de alunos da Rede Oficial de Ensino Básico. Para a formação de alunos competentes comunicativamente, ao final, da escolarização torna-se necessária a formação de professores competentes argumentativamente. Para tanto, acreditamos que a teoria do agir comunicativo, de Jurgen Habermas, venha a colaborar nesse sentido.
\end{abstract}

Palavras-Chave: Ensino de Ciências, Formação de Professores, Agir Comunicativo, Questões Sociocientíficas

\begin{abstract}
The objective of this paper is to present a theoretical proposal for the training of teachers of mathematics and science at the interface of communicative action and socio-scientific issues. In this paper we argue for the need for a continuous training of teachers if we are to be interested in developing the scientific training of students from the public school system. To form communicatively competent students, by the end of schooling, becomes necessary the training of argumentatively competent teachers. Therefore, we believe that the theory of communicative action by Jurgen Habermas, will cooperate to this end.
\end{abstract}

Key-Words: Science Teaching, Teacher Education, Action Communicative, Socio-scientific Issues

\footnotetext{
${ }^{1}$ Programa de Pós-Graduação em Educação para a Ciência - UNESP - Bauru

${ }^{2}$ UNICAMP

AMAZÔNIA - Revista de Educação em Ciências e Matemáticas V.9 - no 17 - jul. 2012/dez. 2012, p.141-160
} 


\section{INTRODUÇÃOO}

A proposta deste artigo é estabelecer um diálogo teórico entre o tratamento das questões sociocientíficas e a formação continuada de professores de Ciências e Matemática pelo viés teórico-crítico da teoria do Agir Comunicativo de Jurgen Habermas. Isso porque há um grande número de pesquisas no ensino de ciências, particularmente, na interface CTSA, que argumentam sobre a necessidade de formação de aluno críticos, aptos para tomada de decisões na sociedade científico-tecnológica contemporânea. De uma maneira geral, tais pesquisas defendem a necessidade de os alunos compreenderem que as disciplinas científicas escolares são fulcrais para o entendimento da evolução da ciência e tecnologia, inclusive, para o entendimento das problemáticas advindas dos produtos que estão na interface entre ciência e sociedade.

Nessa direção, Kolsto (2000) afirma que é de fundamental importância a participação da população nos debates em torno de questões que envolvam os produtos da ciência e tecnologia. No entanto, para estar apto a estas discussões, torna-se necessário compreender certos aspectos que caracterizam o fazer científico e o impacto do desenvolvimento científicotecnológico na sociedade contemporânea. Muitos destes aspectos estão relacionados com a ideia de ciência para cidadania, a qual defende a necessidade de enfatizar a ciência como um processo social, revelando o caráter humano, os valores envolvidos e os limites da ciência, assim como defende uma formação em ciências que esteja fortemente ligada ao uso do conhecimento científico escolar, bem como dos aspectos axiológicos da natureza da ciência, a fim de potencializar a participação da população nos debates científicos e tecnológicos.

Diante das necessidades formativas dos alunos, questionamos: em que medida os professores de ciências e matemática legitimam as questões sociocientíficas e estão aptos a implementá-las em sala de aula? Ou seja, em que medida a prática pedagógica dos professores está voltada para os objetivos do ensino de ciências?

Há uma grande preocupação dos professores da Rede Oficial de Ensino Básica em "dar conta" do conteúdo, o que dificulta a inserção de estratégias com práticas argumentativas no contexto de sala de aula, assim como, no diálogo entre os professores no cotidiano escolar. Para Giroux (1997), não há uma ênfase nos alunos para lerem o mundo criticamente, mas, sim, em desenvolver habilidades de leitura de forma mecânica, a qual impede a produção de sentido e significado sobre aquilo que é dado como factual. Não há um incentivo à problematização das coisas que estão no mundo. A linguagem atua como mecanismo de 
transmissão de informações. A racionalidade que orienta o discurso no contexto escolar é instrumental e imperativa. Não há espaço para o exercício da argumentação crítica para ocorrer o entendimento das tensões e obstáculos do cotidiano escolar e dos eventos do mundo de uma maneira geral.

A ausência de um espaço amplo de comunicação no ambiente escolar dificulta o processo de formação entre professores, como nas relações aluno-professor e aluno-aluno. É no processo comunicativo, livre de coerções, com o exercício efetivo da argumentação, que as pessoas se entendem, entendem as coisas do mundo e promovem mudanças no status quo.

Neste artigo, buscarmos discutir que, para o desenvolvimento da formação científica escolar de alunos, é imprescindível a formação dos professores de ciências e matemática frente aos mesmos objetivos. Diante disto, apresentamos a Teoria do Agir Comunicativo de Jurgen Habermas como aporte teórico para a compreensão da prática discursiva docente e da identificação das possíveis relações que os professores podem estabelecer com as escolas e os saberes teóricos-pedagógicos, assim como com as questões sociocientíficas.

\section{AS QUESTÕES SOCIOCIENTÍFICAS}

O domínio das questões sociocientíficas possui uma estrutura teórica que permite o desenvolvimento dos alunos quanto às questões morais e científicas por meio de processos discursivos e interativos no contexto de sala de aula. Elas possuem como características os seguintes pontos que são apontados por Ratcliffe e Grace (2003, p.2-3):

- Tem base na ciência, e frequentemente se localiza na fronteira do conhecimento científico;

- Envolve a formação de opiniões, escolhas a nível pessoal ou social;

- São frequentemente relatados pela mídia;

- Possui informações incompletas e conflitos de evidências científicas;

- Possui dimensões locais ou globais ligadas a estruturas políticas e sociais;

- Pode envolver elementos de desenvolvimento sustentável;

- Envolve valores e raciocínio ético;

- Pode requerer algum entendimento de probabilidade ou risco;

- São tópicos frequentes na vida cotidiana;

Assim, as questões sociocientíficas possuem uma estrutura teórico-pedagógica que permite vislumbrar o desenvolvimento da argumentação, da natureza da ciência, o 
entendimento das relações entre outras áreas do conhecimento humano com a dimensão científica, a análise de informações de divulgação científica. Por outro lado, há uma proximidade das questões sociocientíficas com as dimensões morais, as quais permitem que os estudantes "tematizem o assunto e passem a refletir sobre algo que, aparentemente, parecia trivial e previamente tido como definido" (GUIMARAES, 2010, p.06).

As questões sociocientíficas são caracterizadas como temas científicos-tecnológicos de fronteira da ciência, como por exemplo, pesquisas com células troncos, xenotransplantes, aquecimento global, vacinas dentre outros. São temáticas que a priori não tem solução, mas que o processo de entendimento exige dos cidadãos o uso do conhecimento científico escolar, uma concepção de ciência como atividade humana, do raciocínio ético e moral e de competência argumentativa.

Zeidler et al. (2005) afirmam que realmente existe a necessidade de desenvolver a proposta teórica para o domínio das questões sociocientíficas com o intuito de atender aos objetivos de engajar a população em temas de ciência e tecnologia. Porém, essa estrutura teórica necessita ser suficientemente flexível a fim de potencializar o desenvolvimento dos aspectos morais, da estrutura do conhecimento científico, emotivos e argumentativos inerentes a um dilema. Os autores pontuam que a compreensão deste domínio de investigação e o desenvolvimento de uma estrutura pedagógica permitiu o surgimento de quatro grandes linhas de pesquisa: (1) natureza da ciência, (2) questões discursivas em sala de aula, (3) questões culturais e (4) estudos de caso.

A natureza da ciência caracteriza-se como um ponto importante das questões sociocientíficas, pois, permite analisar a variedade de pontos de vistas epistemológicos que muitos alunos utilizam para avaliar uma evidência científica, inferir ou elaborar uma hipótese frente a uma problemática da ciência. Por outro lado, a dimensão discursiva está relacionada com o potencial controverso destas questões, as quais potencializam o desenvolvimento da prática discursiva em sala de aula, como por exemplo, a elaboração de argumentos. O desenvolvimento de um processo argumentativo permite que o núcleo de crenças epistemológicas e morais dos alunos sejam expostos por meio do uso de raciocínios lógicos dedutivos. A exploração das estruturas argumentativas possibilita que os educandos percebam as premissas que constituem a base do raciocínio e averiguem a plausibilidade frente à questão que está sendo discutida. Quanto aos aspectos culturais, estes estão relacionados com elementos que envolvem o respeito e a tolerância com a diversidade de perspectivas, muitas destas, oriundas do núcleo de crenças pessoais. Por fim, os estudos de caso contribuem para 
que os professores de ciências, assim como os alunos tenham consciência moral e compromisso para o entendimento adequado das diferentes perspectivas que estão em jogo numa questão sociocientífica, como também, avaliar em que medida outros setores da sociedade determinam via dinheiro e poder os caminhos que percorrem certos empreendimentos científicos controversos (ZEIDLER et al., 2005).

Assim, é importante promover um ensino de ciências que leve em consideração as seguintes características: processos de investigação, conflito, argumentação, compromisso, tomada de decisão e engajamento frente à miríade de conhecimentos necessários para análise e compreensão da temática. $\mathrm{O}$ exercício destes elementos pedagógicos permite que o professor tenha entendimento de como ocorre a construção do conhecimento no contexto escolar e a importância da linguagem como meio de entendimento dos fatos do mundo da vida.

As questões sociocientíficas permitem o desenvolvimento significativo dessas novas estratégias cognitivas, assim como os conceitos científicos, políticos, morais e éticos envolvidos potencializam o exercício da racionalidade de forma mais complexa, atendendo não apenas à racionalidade instrumental, que possui um papel na construção do conhecimento, mas também ao uso moral da racionalidade, ou seja, considerar quais aspectos são importante para seleção dos melhores fins para todos. (LONGHI, 2005).

Para poder avaliar uma temática na interface ciência-sociedade, torna-se necessário utilizar certos questionamentos no intuito de sistematizar critérios e organizar a abordagem metodológica no contexto de sala de aula. Por exemplo, é importante avaliar: a) a utilidade do conhecimento proposto e as habilidades que serão realçadas para a formação do aluno; b) se o conhecimento abordado proporciona o desenvolvimento da responsabilidade social e do entendimento da articulação ciência e sociedade; c) se os conhecimentos matemáticos e científicos intrínsecos a proposta são importantes na perspectiva histórica do conhecimento humano; d) se os valores filosóficos presentes na temática são importantes para o questionamento sobre a qualidade de vida, bem-estar, vida e morte (ZEIDLER; KEEFER, 2003).

Nesse contexto, para estar coerente com os pressupostos de uma educação para Ciência, é necessário desenvolver contextos de formação que possibilitem o entendimento dos conhecimentos científicos, sociais, históricos, políticos e ético-morais que fazem parte de uma concepção de natureza aberta da ciência, ou seja, desnaturalizada. Nessa perspectiva, pode-se 
dizer que as questões sociocientíficas vão ao encontro de uma educação para ciência que contribui para o processo de formação coletiva de atores sociais via prática comunicativa.

\title{
A TEORIA DO AGIR COMUNICATIVO
}

A Teoria do Agir Comunicativo concebe que a sociedade moderna contemporânea é formada pelo mundo da vida e sistema.

O mundo da vida é caracterizado como o espaço em que ocorrem as comunicações livre de coerções, sem distorções. Local, no qual a linguagem não é utilizada como instrumento de transmissão de informações. Mas, ao contrário, ela possui papel fundamental na construção do conhecimento e na compreensão do mundo. Segundo Mühl (2003), a linguagem é uma ação humana, faz parte da prática social, ação do sujeito no mundo como mediadora das trocas intersubjetivas entres os atores sociais sob regras determinadas.

Para Habermas (2012), a estrutura do mundo da vida é composta pela cultura, sociedade e personalidade. Assim:

\begin{abstract}
A cultura constitui o estoque ou reserva de saber, do qual os participantes da comunicação extraem interpretações no momento em que tentam se entender sobre algo no mundo. Defino a sociedade por meio das ordens legítimas pelas quais os participantes da comunicação regulam sua pertença a grupos sociais, assegurando a solidariedade. Interpreto a personalidade como o conjunto de competências que tornam o sujeito capaz de fala e de ação - portanto, que o colocam em condições de participar de processos de entendimento, permitindo-lhe afirmar sua identidade. $\mathrm{O}$ campo semântico dos conteúdos simbólicos, o espaço social e o tempo histórico constituem as dimensões em que os atos comunicativos se realizam. As interações que formam a rede prática comunicativa cotidiana configuram o meio pelo qual a cultura, a sociedade e a pessoa se reproduzem. E tais processos de reprodução se estendem às estruturas simbólicas do mundo da vida (HABERMAS, 2012, p. 253).
\end{abstract}

As três estruturas que constituem o mundo da vida são interdependentes nos aspectos funcionais. Por exemplo, a reprodução da dimensão cultural do mundo da vida é responsável por manter a tradição e coerência daqueles "saberes" que foram constituídos ao longo do tempo. É a manutenção cultural desses saberes, por meio do exercício da racionalidade comunicativa, que permite o exercício da prática cotidiana. Torna-se possível constatar a 
importância da dimensão da cultura e seus aspectos funcionais no mundo da vida, quando ocorrem dificuldades ou conflitos no processo de reprodução cultural que contribuem para a perda de sentido ou crises de orientação e legitimação. Um exemplo disto seria a dificuldade que os professores de ciências sentem na dinâmica entre professor-aluno e os saberes dos alunos com relação aos saberes de senso comum do aluno. Ora, a dificuldade de validação/legitimação dos saberes dos alunos via racionalidade comunicativa pelo professor que declara o conhecimento escolar, potencializa a perda de sentido entre o saber do aluno e o saber escolar, por conseguinte, há uma deterioração do real significado da escola, do conhecimento escolar na vida do aluno. Estes aspectos sintomáticos dos conflitos que obstaculizam a reprodução cultural são decorrentes das insuficiências dos saberes culturais que os atores (no exemplo, os alunos) dispõem para articular e empreenderem um processo argumentativo para o entendimento dos elementos que são válidos ou não numa determinada situação. Já os aspectos funcionais da sociedade se articulam por meio das normatizações que um grupo de pessoas legitima para poder praticar a coordenação de ações frente ao tema em problematização. Além, do aspecto organizacional, as normas potencializam o fenômeno da solidariedade coletiva, a qual está relacionada com uma ética discursiva, ou seja, que entre os participantes ocorra o reconhecimento da fala do outro. Isto permite a estabilização das identidades grupais via solidariedade coletiva. A não manutenção dos aspectos funcionais da sociedade possibilita o surgimento de conflitos e anomia. Isso porque os participantes não conseguem mais promover a coordenação de ações em novas situações com os elementos normativos que antes organizavam e mantinham uma ética discursiva. Ora, a insuficiência destas normatizações corrompe a solidariedade coletiva e desestabiliza as identidades grupais.

As dimensões da cultura e da sociedade são responsáveis por assegurar vivências experienciadas, as biografias das pessoas no mundo, como, também, a identificação de si para com outro, a ética coletiva e o auto-reconhecimento como pessoa responsável no mundo que participa de ações coletivas. Caso haja dificuldade em relação ao desenvolvimento e significação das histórias de vida, de uma ética discursiva, como também, da responsabilidade coletiva, é possível constatar aspectos sintomáticos das patologias psicológicas, como alienação, depressões e outras. Estas patologias são manifestações da insuficiência dos atores sociais em desenvolverem uma prática linguística intersubjetiva voltada para o entendimento. Ora, diante disto o sistema da personalidade (por exemplo, os professores da rede pública básica de ensino) não consegue se manter, a não ser por meio de ações estratégicas como 
autoproteção, por exemplo, as resistências de professores da rede básica de ensino em problematizar a própria prática e romper processos tradicionalistas de ensino e aprendizagem.

Assim, essas distinções são importantes para que haja o enfrentamento por meio de um agir comunicativo das problemáticas decorrentes da invasão sistêmica no mundo da vida. Esse enfrentamento permite assegurar a integridade das estruturas do mundo da vida e evitar a prevalência das patologias citadas acima.

Para que ocorra a comunicação livre de coerções é imprescindível o uso das pretensões de validade. Habermas (2012b), afirma que estas pretensões são regras tácitas ao homem na sua relação com o mundo. Nesta perspectiva, a ideia de "regra" não está associada a uma visão de mundo solipcista da existência do sujeito (LONGHI, 2005). Ao contrário disto, o sujeito se torna existente a partir do momento em que se relaciona comunicativamente com outros participantes por um principio ético discursivo, o qual está relacionado com as pretensões de validade.

O contexto comunicativo na perspectiva habermasiana, assim como a competência comunicativa dos participantes, é orientado pelas pretensões de validade. Se considerarmos uma situação em que um falante lança uma proposta sobre algum fato ou evento, as pretensões de validade deverão ser consideradas. Logo,

(...) a validade do ato de fala ${ }^{3}$ levado a cabo dependerá de esta ação se encontrar ou não em conformidade com uma base normativa reconhecida. Enquanto uma frase gramatical cumpre as exigências da compreensibilidade, uma expressão bem sucedida deverá satisfazer três pretensões de validade adicionais: ser considerada verdadeira pelos participantes do ponto de vista em que representa algo que existe no mundo, ser considerada sincera da perspectiva em que expressa uma intenção do falante e, por fim, ser considerada acertada do ponto de vista em que se encontre em conformidade com as expectativas socialmente reconhecidas (HABERMAS, 2002, p.49).

Nesse contexto, Habermas (2002) entende por "competência comunicativa", a capacidade de o falante orientar a própria fala para o entendimento durante um contexto comunicativo com diversos participantes. A fala orientada para o entendimento parte do pressuposto de que o falante deverá ser capaz de estruturar uma frase de forma inteligível, assim contribuindo para que o ouvinte possa compreender o ponto de vista externalizado pelo falante; ao externalizar o seu ponto de vista, o falante expressa as intenções da proposta

$3 \quad \mathrm{O}$ ato de fala na perspectiva habermasiana é caracterizado quando há pelo menos dois participantes numa situação de diálogo. 
formulada, no intuito de que o ouvinte possa confiar nas suas intenções; por fim, em cada ato de fala durante o processo intersubjetivo há necessidade de o falante se orientar pelos valores sociais aceitáveis, ou seja, atentar para as regras normativas do contexto comunicativo.

Na perspectiva das pretensões de validade, os atos de fala ${ }^{4}$ compõem uma parte do discurso e avaliam a força ilocutória ${ }^{5}$ de pontos de vista durante as relações interpessoais num contexto comunicativo (HABERMAS, 2002). São estas relações intersubjetivas que se tornam importantes no contexto da teoria da ação comunicativa.

A grande ideia do conceito do agir comunicativo é que a linguagem tem a função de coordenar ações, de socializar sujeitos de ação, além das ações orientadas para o consenso.

Durante o processo de comunicação, há diferentes usos que os atores sociais fazem da linguagem para buscar o entendimento sobre algo no mundo externo. Ao tentar compreender fatos/eventos do mundo exterior de forma intersubjetiva, o sujeito se volta sobre si mesmo, tornando-se objeto de si, empreendendo, assim, um processo de auto-reflexão, ao mesmo tempo em que se apropria do mundo. Essa perspectiva intersubjetiva de compreensão de algo do mundo é interpretada de maneira diferente pelos participantes de uma comunicação. Isso permite que as diferentes visões de mundo contribuam para um processo de descentralização egocêntrica que cada um tem de si e do mundo, desde que tenham como pressuposto a consideração dos pontos de vista e interesses de cada participante envolvido no intuito de alcançar um consenso. (HABERMAS, 2004).

$\mathrm{O}$ ato de fala possui uma função importante para Habermas. Isso porque é por meio do ato de fala que os participantes de uma discussão conseguem perceber as intenções dos outros atores envolvidos no contexto comunicativo. $\mathrm{O}$ ato de fala representa uma ação, pois ao pronunciar uma promessa ou um aviso o falante intervém no mundo. No entanto, é importante considerar que, no contexto comunicativo, para existir o ato de fala, o falante deverá entenderse com os outros participantes acerca de algo no mundo (HABERMAS, 2002).

Ao considerarmos um contexto comunicativo, no qual se busca o entendimento, $\mathrm{o}$ ato de fala possui características peculiares que estão relacionados com o uso que se faz da linguagem. Por exemplo, se discutimos aspectos normativos da interação do grupo de atores sociais estamos nos reportando a atos de fala regulativos; se estamos discutindo a respeito de

\footnotetext{
${ }^{4}$ Ato de fala: toda ação que é realizada através do dizer. Isso porque todo ato de fala possui uma intenção.

${ }^{5}$ A força ilocucionária está vinculada ao ato ilocucionário: não tem a intenção de apenas constatar uma situação, mas a de protestar ou de advertir sobre um determinado evento.
} 
teorias, conceitos ou princípios da ciência, estamos apresentando atos de fala constativos; e, por fim, se os participantes se reportam a aspectos pessoais no grupo, o ato de fala é caracterizado como sendo expressivo.

\begin{tabular}{|c|c|c|c|}
\hline $\begin{array}{c}\text { Modo de } \\
\text { Comunicação }\end{array}$ & $\begin{array}{c}\text { Tipo de Ato de } \\
\text { Fala }\end{array}$ & Tema & $\begin{array}{c}\text { Pretensão de } \\
\text { Validade Temática }\end{array}$ \\
\hline Cognitivo & Constativo & $\begin{array}{c}\text { Conteúdo } \\
\text { Proposicional }\end{array}$ & Verdade \\
\hline Interativo & Regulativo & $\begin{array}{c}\text { Relação } \\
\text { Interpessoal }\end{array}$ & Acerto e Adequação \\
\hline Expressivo & Confissões & $\begin{array}{c}\text { Intenções do } \\
\text { Falante }\end{array}$ & Veracidade \\
\hline
\end{tabular}

Quadro 1: Modos de Comunicação Fonte: (HABERMAS, 2002, p.88)

Cada tipo de ato de fala está relacionado com a forma como o ator-social faz uso da razão para se relacionar e interpretar os fatos do mundo. Há três tipos de razões: Objetiva, Social e Subjetiva. Estas razões são expressas pelo tipo de ato de fala que o indivíduo profere em determinado contexto de comunicação e, por conseguinte, este ato de fala está vinculado a uma pretensão de validade.

\begin{tabular}{|l|l|l|l|}
\hline \multicolumn{1}{|c|}{ Mundo } & \multicolumn{1}{|c|}{ Razão } & \multicolumn{1}{c|}{$\begin{array}{c}\text { Tipo de Ato de } \\
\text { Fala }\end{array}$} & \multicolumn{1}{c|}{$\begin{array}{c}\text { Pretensões de } \\
\text { Validade }\end{array}$} \\
\hline Objetivo & Objetiva & Constativo & Verdade \\
\hline Social & Social & Regulativo & $\begin{array}{l}\text { Acerto de Normas e } \\
\text { Valores }\end{array}$ \\
\hline Subjetivo & Subjetiva & Confissões & Veracidade/Sinceridade \\
\hline
\end{tabular}

Quadro 2: Usos das Razões Fonte: Autor.

Quando o participante de uma discussão orientada para o entendimento faz uso cognitivo/constatativo da linguagem, torna-se necessário que o falante forneça os fundamentos que asseguram a validade cognitiva do ato de fala enunciado. "Os atos de fala constatativos contêm a proposta que nos permite recorrer, se necessário, à fonte experimental de onde o falante retira a certeza de que aquilo que afirma é verdade" (HABERMAS, 2002, p.95). Caso as bases "teóricas" que fundamentam os atos de fala não sejam suficientes para 
responder um questionamento ou esclarecer uma dúvida do ouvinte, torna-se necessário que esta dúvida/problema venha ser problematizada(o) por meio do discurso teórico.

Já no uso interativo/intersubjetivo da linguagem, o falante precisa fornecer justificativas que assegurem as condições normativas/regulativas da importância do ato de fala no contexto de uma discussão orientada para ação comunicativa. Porém, caso tais justificativas não sejam suficientes, instaura-se um problema relacionado com as condições normativas, assim com o objetivo de solucionar tal problemática, a discussão será desenvolvida por meio do discurso prático.

Por fim, no uso expressivo da linguagem, o falante necessita "provar" a veracidade dos atos de fala por meio de esclarecer quais os fundamentos que realmente orientam as intenções expressivas aos atos de fala (HABERMAS, 2002). Caso o falante não consiga exprimir a ideia de veracidade para os ouvintes, a averiguação apenas será possível por meio da observação da coerência comportamental do falante (HABERMAS, 2002). Logo, o que é observado será se, após a enunciação de atos de fala expressivos, o falante de fato está comprometido com aquilo que falou, ou seja, se foi cumprida.

Podemos dizer que as pretensões de validade que caracterizam os usos cognitivo, interativo/intersubjetivo e expressivo da linguagem e, por conseguinte, os atos de fala são as seguintes:

1) PRETENSÕES DE VERDADE - obrigação de fornecer fundamentos;

2) PRETENSÕES DE ACERTO - obrigação de fornecer justificações;

3) PRETENSÕES DE SINCERIDADE - obrigação de demonstrar a sua fiabilidade.

\begin{tabular}{|c|c|c|c|}
\hline Realidade $^{\text {Domínios da }}$ & $\begin{array}{l}\quad \text { Modos de } \\
\text { Comunicação: Atitudes } \\
\text { Básicas }\end{array}$ & de Validade & $\begin{array}{r}\text { Funções } \\
\text { Gerais do Discurso }\end{array}$ \\
\hline $\begin{array}{l}\text { "O" mundo de natureza } \\
\text { externa }\end{array}$ & $\begin{array}{l}\text { Cognitivo: } \\
\text { objetivante }\end{array}$ & Verdade & Representação de Fatos \\
\hline $\begin{array}{lll}\text { "Nosso" } & \text { mundo } & \text { de } \\
\text { sociedade } & & \end{array}$ & $\begin{array}{ll}\text { Interativo: } & \text { atitude } \\
\text { conformativa } & \end{array}$ & Acerto & $\begin{array}{l}\text { Estabelecimento de } \\
\text { relações interpessoais } \\
\text { legítimas }\end{array}$ \\
\hline $\begin{array}{l}\text { "Meu" mundo de } \\
\text { natureza interna }\end{array}$ & $\begin{array}{l}\text { Expressivo: } \\
\text { expressiva }\end{array}$ & Sinceridade & $\begin{array}{l}\text { Revelação da } \\
\text { subjetividade do falante }\end{array}$ \\
\hline Linguagem & ---------- & Inteligibilidade & -- \\
\hline
\end{tabular}

Quadro 2: Domínios e Funções do Discurso. Fonte: (HABERMAS, 2002) 
Enquanto o mundo da vida é regulado pelas pretensões de validade no intuito de potencializar uma ação comunicativa voltada para o entendimento entre os atores participantes, o sistema, pelo contrário, é regulado pelo dinheiro e poder. A linguagem, na perspectiva do sistema, é instrumento para transmissão de informações. O uso da linguagem é imperativo e não interacionista. O agir responsável pelo sistema é o teleológico, e a razão que o orienta este agir, é a instrumental.

\section{A CONTRIBUIÇÃO DA TEORIA DA AGIR COMUNICATIVO NO TRATAMENTO DAS QUESTÕES SOCIOCIENTÍFICAS}

Atualmente, são inúmeras as manchetes nos meios de comunicação divulgando os mais recentes produtos advindos da dimensão da ciência e tecnologia, principalmente, em setores como biologia, química e física. Grande parte destes setores se relaciona com temáticas que envolvem transgênicos, células-tronco, produção de energia, aquecimento global, medicamentos, entre outros.

Hoje, os movimentos nos setores de Ciência e Tecnologia têm como característica a multidisciplinariedade, ou seja, para compreender as inovações nestas áreas é necessário se apoiar nos conhecimentos da Física, Química, Biologia, Matemática, Economia e etc. A ideia de um fazer científico neutro, à parte das consequências sociais é inviável.

Sabemos que grandes indústrias, como a do tabaco e outras, investem em pesquisas científicas para inovar e potencializar seus produtos no mercado capitalista. Assim, os produtos da ciência têm um impacto social que pode ser construtivo ou destrutivo, possui um valor. Porém, os pressupostos positivistas que orientam o fazer científico potencializam a dicotomia entre a gênese do conhecimento e a validade social. Já que o positivismo assegura que o método científico do fazer ciência não possui nenhuma relação com a dimensão normativa. Ou seja, o método científico é a histórico (MÜHL, 2003).

Esta separação entre o referencial metodológico positivista e as implicações sociais levanta problemas graves sobre a legitimidade do produto científico-tecnológico. Para o cientista positivista, fundamentações das decisões sociais para um determinado produto científico não fazem parte do planejamento, a não ser quando estão atreladas a fatores empíricos, que ressaltem o agir com respeito afins. 
Dessa forma, o positivismo mantém uma clara separação entre ser e dever-ser, considerando que apenas o primeiro é suscetível de análise e planejamento racional. Com isso fica descartada a possibilidade de se pensar uma alternativa emancipativa para a sociedade, pois, o máximo que se pode obter é um planejamento do destino da humanidade, através de técnicas sociais adequadas (MÜHL, 2003, p.95).

Nessa perspectiva, há uma redução dos aspectos morais da racionalidade implicando na suspensão do processo de autorreflexão. O fazer científico-tecnológico se finda em ações técnicas vinculadas aos imperativos de dinheiro e poder. Se anteriormente o objetivo do projeto iluminista era libertar o homem dos grilhões da escuridão, hoje, temos um aprisionamento do homem em decorrência dos interesses sociais estarem determinados em função da manutenção do sistema econômico (MÜHL, 2003).

Assim, o conhecimento científico assume um caráter cientificista e passa a legitimar uma ideologia que favorece o processo de manipulação e despolitização dos atores sociais. Isto ocorre em função da ausência de problematização das diferenças entre interesses e necessidades coletivas e individuais. Assim, há o desenvolvimento de diversas patologias, sendo uma delas:

(...) a redução das possibilidades de reação contra o sistema por parte de grupos sociais ou das classes, na medida em que o Estado desenvolve não somente mecanismo de controle e da manipulação através da mass media, mas também, políticas de compensação que asseguram a lealdade das massas (MÜHL, 2003, p.96).

A apresentação e a formação da opinião pública em relação aos produtos da ciência e da tecnologia determinam o aumento dos níveis de consumo, a crença de que a organização da estrutura da sociedade, assim como de uma grande parte dos problemas que nelas eclodem são de responsabilidade de tecnocratas e que, para a população, cabe apenas acatar as decisões de especialistas, isso porque a felicidade e o bem-estar dela dependem exclusivamente dos tecnocratas (MÜHL, 2003).

Ora, diante disto, como podemos avaliar o impacto científico-tecnológico no nosso mundo privado? A maneira como os produtos são apresentados para a população são livres de conflitos ou controvérsias à primeira vista. Isto porque, segundo Ulrich Beck (1995), estamos vivenciando uma sociedade de risco que surgiu em decorrência do próprio processo de modernização, sendo esta, também, indiferente aos efeitos colaterais desta dinâmica científico-tecnológica. 
A ausência de um processo reflexivo sobre as necessidades e interesses do bem-estar científico-tecnológico, ou seja, um comportamento hiperindividualista e de aceitação do que é dito pelos especialistas, é o que corrobora o modo de ser da sociedade contemporânea.

Um exemplo interessante para caracterizar o que seria a ideia de risco e a incerteza frente a uma possível solução científico-tecnológica, seria o caso do campo eletromagnético, produzido por aparelhos celulares e outros dispositivos de radiofrequência (televisores, antenas de celulares e etc.).

Ao se falar de uma educação para Ciência reconhece-se a necessidade de formação de atores sociais que estejam aptos a exercer uma liberdade comunicativa frente às relações da Ciência e Sociedade.

Logo, pode-se dizer que a escola é o lócus em que ocorre a reprodução dos conhecimentos construídos e reconstruídos ao longo da evolução da sociedade. A escola possui uma identidade própria e uma função social pré-determinada. Cabe a ela "servir como instância de formação intelectual e moral dos indivíduos e de formação técnica para o atendimento das necessidades do mercado emergente, decorrente do desenvolvimento industrial" (MUHL, p. 270, 2003). Segundo Longhi (2005), é possível reconhecer que a escola possui a função de reproduzir as tradições culturais e outros valores do mundo sistêmico, como, também, de assegurar o exercício da crítica frente aos novos fatos da sociedade contemporânea e do conhecimento, buscando, por meio do agir comunicativo, transformações dos significados coletivos e interpretativos dos fatos do mundo moderno.

A função social da escola pode ser desvelada por meio da reprodução cultural do conhecimento construído historicamente por meio de saberes selecionados e inseridos no currículo escolar. Por outro lado, o exercício da crítica só se torna assegurado na inserção de temáticas controversas no domínio do currículo. Ora, como exemplo de temática controversa, temos as problemáticas ambientais, as drogas, a pobreza e as questões sociocientíficas.

É nesse ponto em que a teoria do agir comunicativo potencializa a reflexão sobre as questões sociocientíficas como sendo um recorte do pano fundo do mundo da vida que necessita ser tematizado.

No processo de tematização das questões sociocientíficas, segundo a teoria do agir comunicativo, o ator social precisa fazer menção ao mundo objetivo (teorias, leis e princípios), ao mundo social (normas nas interações sociais) e ao mundo subjetivo (impressões pessoais, narrativas biográficas e etc.) no intuito de agir com responsabilidade e 
autonomia sobre as coisas do mundo (SUTIL, 2009). Nesse processo, a linguagem é o meio pelo qual os atores se reportam a cada um dos três mundos no intuito de alcançar um consenso por meio do entendimento, o qual é regulado pelas pretensões de validez. Diante disso, o consenso está vinculado com aquilo que os participantes de uma discussão procuram ter em comum, ou seja, a constituição de um conhecimento sobre uma questão sociocientífica.

Outro ponto importante da teoria da sociedade habermasiana, que vem contribuir com a discussão das questões sociocientíficas, é sobre o uso da razão comunicativa. Há três maneiras de utilizar a razão comunicativa pelos atores sociais no contexto comunicativo, segundo Habermas. A primeira é o uso pragmático da razão, a segunda o uso ético da razão e a terceira o uso moral da razão. $\mathrm{O}$ uso pragmático da razão comunicativa está orientado pelos fins. Já o uso ético está orientado para aquilo que é bom para o indivíduo e para sociedade. Por fim, o uso moral da razão comunicativa está voltado para as questões de justiça, ou seja, o que é correto. Ora, o que irá orientar os usos da razão pelos participantes são os interesses envolvidos no contexto de comunicação (LONGHI, 2008).

O entendimento dos usos da razão comunicativa é de importância fulcral no contexto do ensino de ciências, particularmente, na dimensão das questões sociocientíficas. Isto porque ele leva a discutir os impactos da ciência e tecnologia no mundo. O homem sempre buscou discutir o que é bom e justo para todos. A cultura ocidental nunca abandonou o projeto de encontrar uma ética e uma moral universal (LONGHI, 2008, p.77).

As inovações na ciência e na tecnologia demandam ao homem a autorreflexão quantos aos aspectos éticos e morais dos produtos científico-tecnológicos. Há uma imensa dificuldade em estabelecer critérios para uso da razão pragmática, ética e moral no contexto da sociedade científico-tecnológica. Isto porque, os interesses e motivações que contribuem para o avanço da ciência e da tecnologia, muitas vezes, estão vinculados aos imperativos corporativistas e também à natureza dos produtos que são bons e justos para a promoção do bem-estar social (HABERMAS, 2006; LONGHI, 2008).

O uso pragmático, ético e moral da razão comunicativa diante dos avanços da sociedade contemporânea permite que os atores sociais sejam movidos ao exercício da autocompreensão frente aos conflitos e incertezas técnico-científicas. Segundo Longhi (2008), o exercício da autocompreensão depende dos modelos interpretativos que estão articulados a um determinado contexto cultural do sujeito. As interpretações que os sujeitos fazem sobre determinado evento do mundo fazem parte da constituição da identidade do mesmo. É a 
cultura, na qual o ator social está imerso, que irá orientar o próprio agir diante as situações do mundo.

Diante destas demandas sobre o que se deve fazer quanto aos impactos da ciência e tecnologia na vida privada, como também no meio ambiente, é que se torna importante o uso prático (ético e moral) da razão comunicativa, que não esteja fundamentado no sujeito, mas, sim, num contexto intersubjetivo e solidário que garanta o enfrentamento coletivo deste desafio da sociedade contemporânea.

Esta perspectiva de enfrentamento permite que ocorra a constituição da vontade coletiva dos atores sociais para deliberação de temas em comum. Isso permite a unificação da razão prática com a vontade soberana de direitos humanos e democracia, pois, a vontade coletiva do povo, é legítima para legislar (HABERMAS, 1990). A soberania popular só deve poder manifestar-se ainda sob as condições discursivas de um processo, em si diferenciado, de formação de opinião e de vontade (HABERMAS, 1990, p. 102).

Logo, a formação de opinião e de vontade está intimamente relacionada com a ética discursiva de Habermas, "a qual se refere aos pressupostos da comunicação que cada um de nós intuitivamente fazemos sempre quando estamos dispostos de argumentar seriamente" (DUTRA, 2005, p. 151).

Os pressupostos de comunicação, segundo o agir comunicativo, são as pretensões de validade que orientam o contexto comunicativo para o consenso. Segundo Dutra (2005), à própria facticidade do mundo, da aceitação e vigência subjaz um reconhecimento tácito destas pretensões de validade. Isso porque, quando um falante se posiciona e apresenta uma argumentação em relação ao tema em debate, pressupõe que todos o ouçam. A validação do argumento proferido pelo falante dependerá das pretensões serem aceitas ou não pelos participantes. A aceitabilidade ou não está vinculada ao principio do discurso teórico ou prático.

A compreensão desse processo é de suma importância e possibilita perceber o potencial cognitivo em relação à ética discursiva, pois, no intuito de convencer os participantes sobre a validade de uma opinião, é necessário sempre se reportar ao discurso (prático ou moral) como forma de reconstruir os saberes proferidos para que estes estejam de acordo com as pretensões de validez. Logo, a ética discursiva rebate o enfoque decisionista de que não é preciso justificar as afirmações e opiniões proferidas. 
O consenso em relação a um contexto comunicativo é o que permite a formação da vontade. Esta vontade racional é constituída de processos argumentativos, sem coações, na qual o que vale é o melhor argumento para a busca intersubjetiva e solidária da verdade. Esse aprendizado ocorre socialmente e a escola é uma instituição com elevado potencial para que os alunos experienciem este processo adquirindo conhecimentos necessários para compreender o agir comunicativo. No entanto, os alunos não estão formados para agirem racionalmente em função da competência linguística necessária para uma ética discursiva e a prática do melhor argumento. Logo, eles são formados para isso. As questões sociocientíficas possuem um importante papel nesta formação.

Como foi discutido, as questões sociocientíficas possuem uma estrutura teóricopedagógica que contribui com o desenvolvimento dos alunos quanto à pratica discursiva, a natureza da ciência, as dimensões éticas e morais e os diferentes aspectos culturais envolvidos na temática. É possível perceber que a temática sociocientífica se aproxima da teoria da ação comunicativa como forma de tematização das coisas do mundo da vida e, por outro lado, uma maneira de resistir às invasões sistêmicas que acabam potencializando as patologias da modernidade, como, por exemplo, depressão, alienação, perda de sentido e esvaziamento cultural.

Ao levarmos as questões sociocientíficas para o contexto escolar, e se tomarmos como pressuposto teórico as orientações do agir comunicativo, precisamos considerar que existe uma assimetria de falas entre professor-aluno. Isso porque o professor aprioristicamente já é um adulto, enquanto o aluno ainda perpassa um processo de formação moral. Diante disto, o que temos é uma ação educativa no contexto das questões sociocientíficas.

Segundo Longhi (2005), a ação educativa é subsidiada pelos pressupostos da teoria da ação comunicativa, sendo que, na ação comunicativa, o objetivo da troca intersubjetiva é o consenso alcançado intersubjetivamente por meio do entendimento via atos de fala, tendo como regras de orientação comunicativa as pretensões de validez. Já na ação educativa, o objetivo da interação intersubjetiva é a aprendizagem de um agir comunicativo, segundo os pressupostos da teoria da ação comunicativa.

\footnotetext{
Na teoria do agir comunicativo o telos é o consenso enquanto que o entendimento é o meio, o instrumento por meio do qual é possível atingir o consenso. Na ação educativa o telos é a aprendizagem das regras próprias do agir comunicativo, enquanto que o processo educativo/formativo é o instrumento orientador do processo de aquisição das regras próprias do agir comunicativo. Tanto no processo do agir comunicativo quanto no processo de ação educativa é fundamental que o
} 
agir para o consenso e a ação para a formação estejam orientadas pelo entendimento (LONGHI, p.138, 2005).

A ação educativa possui o caráter formativo que tem por objetivo orientar os alunos a reconhecer e executar as ações guiadas pelo entendimento para obter um possível consenso. Nesse contexto, as assembleias de sala de aula e a elaboração de normas de convivência são bons exemplos do exercício formativo do agir educativo. A vontade racional e a formação de opinião dos alunos irão depender do nível de desenvolvimento dos alunos, do grau de autonomia e a capacidade argumentativa dos mesmos. Logo, compete ao professor orientar as ações comunicativas em sala de aula. O potencial formativo também está vinculado à diferença de autonomia e à capacidade argumentativa do professor e dos alunos (LONGHI, 2005).

\section{CONSIDERAÇÕES FINAIS}

Há uma naturalização da formação continuada de professores por meio de cursos tradicionais que têm por objetivo o treinamento de professores na dimensão conteudística. Devido a essa tradição, muitos professores possuem resistências a estratégias diferenciadas de formação que potencializam a interação comunicativa no desenvolvimento de propostas interdisciplinares, como, por exemplo, as questões sociocientíficas.

Grande parte das resistências está associada à dificuldade de enfrentamento das insuficiências formativas, sendo que elas podem estar vinculadas ao mundo subjetivo do professor, ou seja, a natureza interna do mesmo, das suas crenças pessoais e/ou biografia.

Por outro lado, podem ocorrer resistências quanto ao mundo objetivo, ou seja, dificuldade de leitura, de entendimento de teorias tanto pedagógicas como o conteúdo específico escolar.

Quanto ao mundo social, alguns docentes pode ter dificuldade de enfrentar as apresentações de seminários, em articular o conhecimento teórico disciplinar com os outros participantes.

Frente a essas adversidades, o discurso teórico caracterizado como sendo o momento quando um participante levanta uma crítica frente aos aspectos teóricos do mundo objetivo (por exemplo, os pressupostos teóricos das questões sociocientíficas) e estabelece um 
processo argumentativo, no qual o que vale é a força do melhor argumento, torna-se um elemento fulcral para tematização das questões referentes à cultura.

Quanto ao discurso prático, este é de extrema valia no intuito de tematizar junto aos potenciais professores em formação a importância do compromisso com o grupo, da articulação entre o falar e agir. O discurso prático surge sempre que algum participante levanta uma crítica frente à pretensão de normas e direito em relação ao comprometimento com o grupo, ou mesmo como forma de tematização das dificuldades do contexto de sala de aula.

Por fim, a crítica terapêutica surge quando há necessidade de tematizar a conduta de algum participante perante o grupo, por exemplo, quando há encenação (ação dramatúrgica) no contexto formativo, o que acabava dificultando o processo de formativo.

Para que ocorra uma formação de professores voltada para responsabilidade e autonomia frente ao tratamento das questões sociocientíficas como qualquer outro tema, é imprescindível a busca do equilíbrio entre os usos da razão objetiva, subjetiva e social. É com base nesse equilíbrio que é possível desenvolver prática comunicativa entre professores voltada para o entendimento.

\section{REFERÊNCIAS}

GIROUX, H. Os professores como intelectuais: rumo a uma pedagogia crítica da aprendizagem. Tradução Daniel Bueno. Porto Alegre: Artmed, 1997. 270 p.

GUIMARÃES, Márcio Andrei. Raciocínio informal e a discussão de questões sociocientíficas: o exemplo das células-tronco humanas. 2011. Tese (Doutorado em Educação para a Ciência) Faculdade de Ciências, Universidade Estadual Paulista, Bauru, 2011.

HABERMAS, J. Racionalidade e Comunicação. Lisboa: Edições 70, 2002.

HABERMAS, J. A ética da discussão e a questão da verdade. São Paulo: Martins Fontes, 2004.

HABERMAS, J. Teoria da Ação Comunicativa I. São Paulo. Martins Fontes 2012 a.

HABERMAS, J. Teoria da Ação Comunicativa II. São Paulo. Martins Fontes 2012b. 
LONGHI, A. A ação educativa na perspectiva da teoria do agir comunicativo de Jürgen Habermas: uma abordagem reflexiva. 2005 Tese de Doutorado. Faculdade de Educação. Universidade de Campinas, Campinas, 2005.

MÜHL, E. H. Habermas: ação pedagógica como agir comunicativo. Passo Fundo: UPF, 2003.

RATCLIFFE M.; GRACE M. Science education for citizenship: teaching socioscientific issues. Maidenhead: Open University Press, 2003

SADLER, T., ZEIDLER, D. Patterns of Informal Reasoning in the Context of Socioscientific Decision Making. Journal Research in Science Teaching. n.01, v.42. 2005.

SADLER, T. Informal Reasoning Regarding Socioscientific Issues: A Critical Review of Research. Journal Research in Science Teaching. n.05.v.41, 2004.

KOLSTO, S. Scientific Literacy for Citizenship: Tools for Dealing with the Science Dimension of Controversial Socioscientific Issues. International Journal of Science Education. v.85, n. 3, p. 291-310, 2001

ULRICH, B.; GIDDENS, A.; LASH, S. Modernização Reflexiva: Política, Tradição e Estética na Ordem Social Moderna. São Paulo: UNESP, 1996.

ZEIDLER, D.; SADLER, D. T.; SIMMONS, L.M.; HOWES, V.E Beyond STS: A ResearchBased Framework for Socioscientific Issues Education. International Journal of Science Education. v.89, n.3, p. 357 - 377, 2005.

ZEIDLER, D.; KEEFER, M. The Role of Moral Reasoning and the Status of Socioscientific Issues in Science Education. In: ZEIDLER, D. (Org.) The Role of Moral Reasoning on Socioscientific Issues and Discourse in Science Education. Dordrecht, The Netherlands: Kluwer Academic Publishers, 2003, p. 07 - 40. 